\title{
Transpondo custos para times de chão de fábrica: um estudo de caso na General Motors
}

\author{
Transposing costs for teams from the factory floor: \\ a case study at General Motors
}

\author{
Daniel Fonseca da Luz
}

Especialista e Mestrando do Programa de Pós-Graduação em Engenharia de Produção e Sistemas, Universidade do Vale do Rio dos Sinos (PPGEPS), São Leopoldo, RS - Brasil, e-mail: danielfonsecaluz@ig.com.br

\section{Resumo}

Este artigo trata-se de estudo de caso realizado no ano de 2010 em uma grande montadora automotiva localizada na cidade de Gravataí, RS, a General Motors do Brasil. Sob a luz de seu sistema corporativo de produção, este artigo mostra como os custos são apresentados para o chão de fábrica, utilizando quadros de indicadores de desempenho de times de trabalho, mais precisamente na categoria de custos, focalizando a área técnica - manutenção de ferramentas. O artigo inicia contextualizando a empresa e o tema estudado, passando para a metodologia empregada e, posteriormente, chegando ao referencial teórico com a revisão de conceitos como perdas, custos e construção de indicadores. Na parte empírica do trabalho é apresentada a prática do desdobramento estratégico do plano de negócios no ambiente fabril, identificando quais os indicadores de custos e como são utilizados para a elaboração de quadros de indicadores de desempenho de times de trabalho, analisando as experiências práticas nesse sentido. Concluiu-se que estruturas robustas de sistemas corporativos de produção e a utilização de indicadores financeiros foram solucionadores para a gestão de custos de equipes de trabalho em uma grande montadora de automóveis.

Palavras-chave: Gerenciamento visual. Chão de fábrica. Sistemas corporativos de produção. Desdobramento estratégico e custos. 


\begin{abstract}
This article seeks to outline the form of case study conducted in 2010 in a large automotive assembly plant in the town of Gravatai, RS, General Motors of Brazil. On the light of their corporate production system, this paper shows how the costs are presented for the factory floor using tables of performance indicators for work teams, specifically the cost category, focusing on the technical area - maintenance tools. The paper begins by contextualizing the company and the subject studied, the methodology used for passing and then coming to a theoretical review of concepts such losses, costs and construction of indicators. On the empirical work is presented to practice the strategic deployment of the business plan in the manufacturing environment, identifying indicators and how costs are used for preparation of tables of performance indicators for work teams, analyzing the experiences in this direction. It was concluded that robust structures of corporate systems of production and use of financial indicators were solvers for cost management of work teams in a major automotive manufacturer.
\end{abstract}

Keywords: Visual management. The factory floor. Corporation production systems. Strategic deployment and costs.

\section{Introdução}

A General Motors (GM), um dos maiores fabricantes de veículos do mundo, teve origem em 1908. Com sede global em Detroit, a GM empregou no ano de 2010 mais de 200.000 pessoas nas principais regiões do mundo e tem operações em 140 países. O maior mercado da GM é o dos Estados Unidos, seguido de China, Brasil, Alemanha, Reino Unido, Canadá e Itália.

A indústria automobilística vem passando por transformações ao longo dos anos. Hoje no País existe um grande número de montadoras em relação a décadas anteriores, ocasionando uma acirrada concorrência no mercado automobilístico (LUZ, 2010), principalmente em plantas que montam veículos ditos "populares", pois trabalham buscando mercado basicamente na dimensão custo.

Nesse contexto de grande corporação e busca por vantagem competitiva por custo, é fundamental que todos comunguem da mesma filosofia dentro de uma corporação e, sendo de extrema importância que todos os funcionários de uma empresa se sintam comprometidos e responsáveis pelo atendimento das metas propostos pela alta direção da companhia, essas metas devem ser tangíveis e de fácil entendimento. Nesse momento entra o quadro de indicadores de desempenho de times de trabalho, sendo este uma importante ferramenta de conscientização, planejamento e controle de equipes de chão de fábrica.

Os quadros permitem que as metas estabelecidas sejam facilmente assimiladas por todos, por meio do business plan deployment - BPD (desdobramento do plano de negócios), que é visualizado pelos quadros de times espalhados por todas as áreas da empresa, cada quadro respeitando as particularidades de cada setor. Neste artigo será analisado somente o indicador "custos" no quadro de indicadores de desempenho da referida equipe de trabalho. A questão de pesquisa que norteia o presente estudo é: como desdobrar indicadores de custo para times de manutenção de ferramental no chão de fábrica de grandes empresas?

\section{Metodologia}

A pesquisa é exploratória e a estratégia escolhida é o estudo de caso. Segundo Yin (2001), essa técnica é indicada quando se examinam acontecimentos contemporâneos e não se pode manipular ou influenciar comportamentos relevantes. Além disso, objetiva-se compreender "como" a empresa automotiva se posicionou em relação à implementação do elemento avaliado.

A coleta de dados será feita em duas etapas: o levantamento de fontes primárias e secundárias. As fontes primárias serão obtidas por meio da revisão bibliográfica dos principais autores que abordam a gestão de equipes e avaliações de desempenho, bem como as teorias que a sustentam o sistema de produção enxuta.

As fontes secundárias serão os levantamentos das ações implementadas dentro da General Motors do Brasil (GMB) para maximizar resultados no que tange a equipes de trabalho e o seu global manufacturing system (GMS). O trabalho analisará, 
baseado em fundamentação teórica, apenas o exemplo prático de qual e como a medição da capacidade de resposta é utilizada nos quadros de indicadores de desempenho de times de trabalho da GMB.

\section{Referencial teórico}

\section{Perdas e o sistema Toyota de produção}

Shingo (1996) apresenta o estudo das perdas (ou desperdícios) no sistema de produção e classifica os desperdícios em sete tipos:

- por superprodução: referentes à produção de itens acima do necessário ou antecipadamente;

- por transporte: referentes às atividades de movimentação de materiais ou informações, as quais usualmente não adicionam valor ao produto;

- por processamento: correspondendo às atividades de transformação desnecessárias para que o produto adquira suas características básicas de qualidade, ou seja, no trabalho que gera partes, são detalhes ou transformações sem necessidade para o produto. Evidentemente, uma transformação desnecessária no produto/processo ou a confecção de partes dispensáveis para se conseguir as funções básicas constituem desperdício, por mais eficiente que seja o processo. A eliminação dessas deficiências de processo deve ser completa e pode ser atingida por meio de técnicas de análise do valor de produto e de processo;

- por fabricação de produtos defeituosos: correspondendo à confecção de itens fora das especificações. Esse tipo de desperdício talvez seja o mais facilmente identificável e mensurável, mas não o menos importante. Uma das maiores necessidades da empresa moderna é a busca incessante pela excelência na eficiência produtiva. Sem isso, ela não se torna competitiva. O trabalho realizado deve ser único e somente quando necessário, evitando qualquer tipo de contato posterior para a execução de revisões ou retrabalhos;
- por movimentação: relacionados à movimentação inútil na execução das atividades, ou seja, à ineficiência da operação propriamente dita. A mensuração desse desperdício está ligada à obtenção de padrões de desempenho para as operações, e sua eliminação é conseguida alcançando-se os padrões necessários e possíveis de executar, analisando conjuntamente a ergonomia dos movimentos;

- por espera: relacionados a questões de sincronização da produção ou constituição de lotes elevados de processamento, graças ao elevado tempo de preparação das tarefas, ou falhas no sistema de informações da organização. Para se evitar esse desperdício, deve-se ter acesso às informações necessárias com precisão e facilidade, além de investir em um processo confiável e sincronizado de produção;

- por estoque: relacionados à existência de estoques, gerando custos financeiros para sua manutenção, custos em virtude da obsolescência dos itens estocados e, principalmente, custos de oportunidade pela perda de mercado futuro para a concorrência com menor lead time. A máxima redução possível de estoques é uma meta que possui impacto no desempenho da organização (SHINGO, 1996).

\section{Custos}

Grandes empresas normalmente criam seus indicadores de custos e de alguma forma tentam repassá-los a suas equipes operacionais, porém nem todas conseguem os resultados esperados, vide as diferenças entre o repasse das preocupações e sua real assimilação no ambiente fabril.

A metodologia utilizada na General Motors baseia-se no controle de custos, visto que denota atenção no valor de insumos que são consumidos na fabricação de peças (estampados) da companhia.

Bornia (2009) afirma que custo de fabricação é o valor dos insumos usados na fabricação de produtos da empresa. Por exemplo, desses insumos são: materiais, trabalho humano, energia elétrica, máquinas e equipamentos, entre outros. Slack (2002) afirma que o desempenho em custo é apenas parte 
de uma medida mais importante, que é o retorno sobre investimento. A utilização da capacidade, o uso econômico de ativos fixos e a administração de estoques também são importantes.

Esses custos são divididos para cada centro de custos, sendo cada departamento um centro e sendo cobrado por tal. Bornia (2009) define que centros são determinados considerando-se o organograma, a localização, as responsabilidades e a homogeneidade do setor.

Salienta-se que a medição de desempenho por meio dos custos apresenta somente a ponta da pirâmide das dimensões totais que devem ser controladas (Figura 1). Haja vista que outros fatores pertinentes à manufatura têm papel fundamental na construção da dimensão custo (SLACK, 2002).

\section{Indicadores}

São procedimentos ou regras que associam práticas a escalas, que descrevem hierarquias ou ordens de preferência. Segundo Bititci et al. (2001), sistemas de medição de desempenho baseados exclusivamente em resultados financeiros não são capazes de desdobrar objetivos de negócios em objetivos de manufatura.
Deve-se ater-se ao fato de que as utilizações isoladas de medidas de desempenho não propiciam nenhuma interpretação, pois estas requerem a finalidade do processo, a estratégia da organização e os índices e/ou históricos que permitam uma análise desses indicadores.

De acordo com Kaplan e Norton (1997), a dinâmica do mercado exige das empresas abordagens que permitam identificar com rapidez novas tendências dos ambientes externos e internos, a fim de detectar desvios e efetuar eventuais correções na gestão. Torna-se, então, imprescindível definir e implementar uma sistemática de indicadores gerenciais capazes de fornecer aos gestores informações sobre vários aspectos do ambiente e do desempenho organizacional, sem o qual não teriam como atingir e manter o rumo da excelência empresarial.

\section{Indicadores de processos}

Em primeiro lugar, a aplicação mais evidente de indicadores de processo está na área fabril. Isso significa associar indicadores capazes de monitorar a sua efetividade às atividades do processo segundo alguma ótica (tempo, custo, qualidade, conformidade,

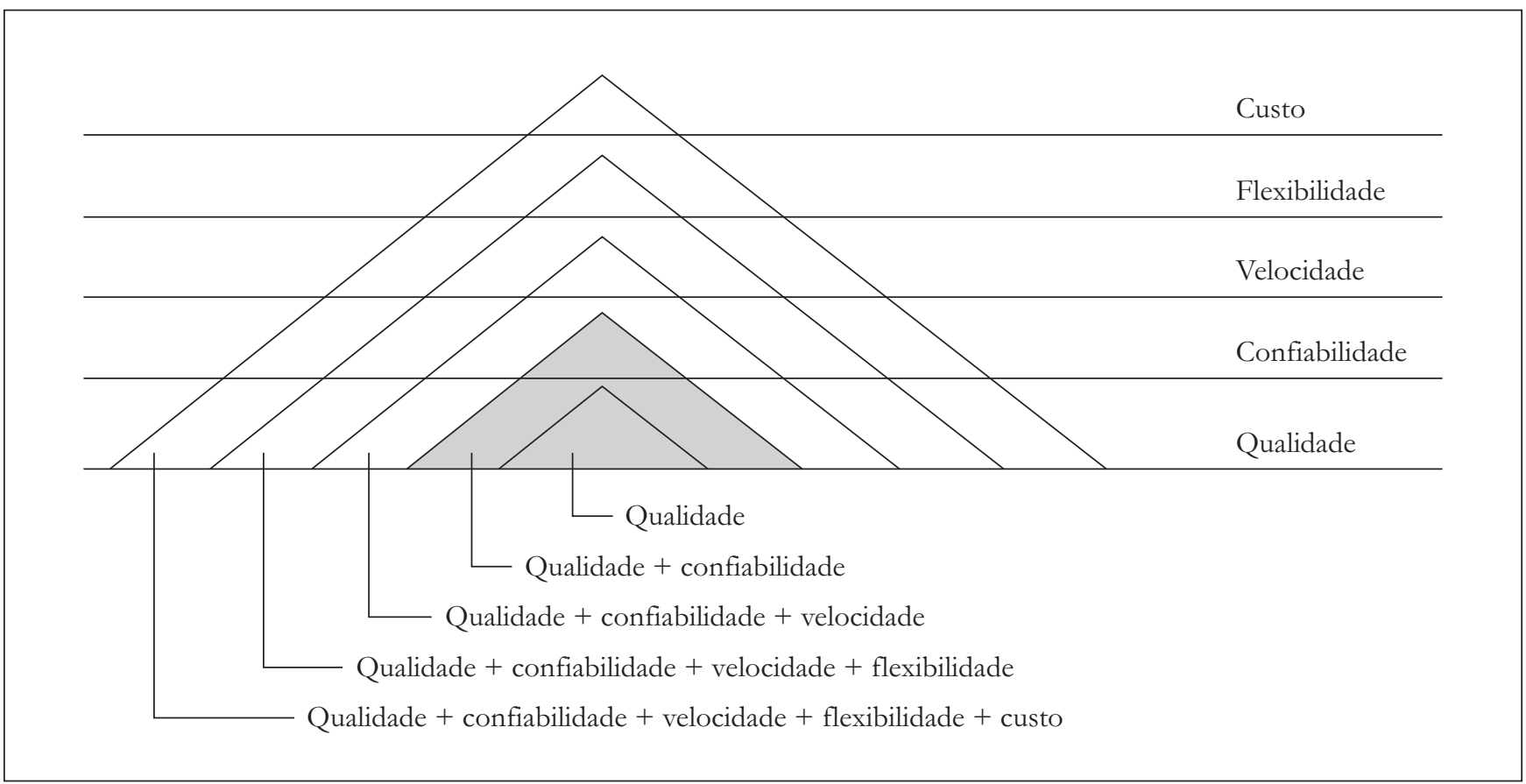

Figura 1 - Modelo de melhoramento em manufatura Fonte: Adaptado de SLACK, 2002. 
etc.). Em segundo lugar, a existência dos processos permitiria questionar se a lógica de cada indicador (local) não teria um impacto global negativo. Essa análise pode precisar de outras informações. Por exemplo, um indicador do tipo carga de máquinas (em princípio, quanto maior a produção / up time melhor) - do processo de produção da estamparia poderia estar levando ao aumento de estoques. Em outras palavras, olhar somente o indicador local pode provocar "distorções de percepção", quando analisamos globalmente os reflexos desses indicadores (ANTUNES JÚNIOR; CAULLIRAUX; NEVES, 1998). A análise por processos pode explicitar esses impactos cruzados que teriam de ser resolvidos conjunta e negociadamente. Em terceiro e último lugar, temos a possibilidade de ligar os indicadores dos processos aos indicadores gerais da organização. Uma das propostas conceituais nessa linha, de maior difusão atualmente, é a do balanced scorecard de Kaplan e Norton, que associa os indicadores de processo aos financeiros, de clientes, de mercado e inovação e de crescimento, porém, sem dar uma consideração maior à microeconomia da organização.

Ao tratar de avaliação de desempenho, Atkinsons (1998) afirma que a mensuração de desempenho é a ação de mensurar o desempenho de uma atividade ou uma cadeia de valores inteira. A avaliação de desempenho é possivelmente a mais importante, incompreendida, e a tarefa mais difícil da atividade gerencial. Um sistema eficiente de avaliação de desempenho operacional contém indicadores-chave de desempenho (medidas de desempenho) que fazem o seguinte:

- consideram todas as atividade e a própria empresa sob a perspectiva do cliente;

- avaliam cada atividade usando medidas de desempenho validadas pelo cliente;

- consideram todas as facetas do desempenho da atividade que afetam diretamente os clientes e que, portanto, devem ser abrangentes;

- fornecem feedback para ajudar os membros da empresa a identificar problemas e oportunizar melhorias contínuas.

Segundo Antunes Júnior e Klipel (2002), empresas japonesas adotam alguns indicadores não financeiros, especialmente nos níveis de supervisão e chão de fábrica. A adoção desses indicadores não financeiros para o controle das atividades do gemba parece razoável na medida em que sejam em pequeno número e articulados com os objetivos financeiros mais amplos. A partir desses indicadores é possível desdobrá-los, para o nível de chão de fábrica, em um conjunto limitado de indicadores não financeiros que possam ser diretamente relacionados com os financeiros. Uma exceção a esse desdobramento de origem financeira é a adoção de indicadores ligados à moral e à segurança, tais como: índice de absenteísmo, segurança no trabalho, etc.

Goldratt (1990) critica a utilização desses indicadores de origem não financeira, especialmente a expansão da utilização destes por toda a fábrica, o que é proposto por certas correntes que adotam o TQC a partir desse tipo de perspectiva.

\section{PDCA}

Plan; do; check; action (PDCA), também chamado de círculo de Deming, é o método de gestão que visa a fazer o círculo girar "planejando; executando; controlando e atuando", sendo usado direta ou indiretamente em grande parte dos sistemas de controle de gestão. O método utilizado para gerenciamento do quadro de indicadores de desempenho de times de trabalho é o PDCA, se o planejamento e a execução forem eficientes, o ciclo PDCA se manterá apenas nas etapas " $d o$ " e "control", pois não há condições fora do normal. Se na etapa de verificação for encontrado um item fora do padrão (fora da meta), deve-se gerar um plano de ação para sanar o problema. Nesse caso, o ciclo PDCA deve ser novamente executado, caso necessário, pois eventualmente o planejamento precisará ser refeito.

Ghinato (1996) afirma, sobre o PDCA, que a rede de processos e operações que compõem a estrutura da produção é totalmente especificada durante a fase de planejamento, contudo, é a função controle que assegura a execução dos processos e operações de acordo com as especificações. O monitoramento deve consistir na comparação dos resultados do controle e execução com as especificações determinadas na fase de planejamento. A aplicação da função monitoramento deve ser capaz de identificar a ocorrência de qualquer deficiência e atestar ou não a eficácia das funções controle e execução.

Segundo Rodrigues (1991), nesse caso estudado e de resto em quase todos os outros em que tange 
a questões operacionais, a autonomia do operador, embora não explícita, se restringe a executar o ciclo PDCA somente dentro do "do" (fazer). A empresa permite a interação do funcionário em âmbito que não resulte em intervenção na estratégia da companhia.

\section{Sistemas corporativos de manufatura}

Um número crescente de grandes fabricantes está embarcando na tendência de promover uma abordagem mais sistematizada no seu processo, visando à aprendizagem e à implantação mais rápida, bem como a uma maior coerência e eficácia. Movidas por essa motivação, essas empresas têm moldado e adequado seu próprio modelo de corporate production system (CPS) (MIYAKE, 2008).

As principais contribuições da evolução dos sistemas de manufatura surgiram nas indústrias automobilísticas, graças à complexidade de componentes e processos necessários à montagem de um veículo (GUARNIERI; HATAKEYAMA; RESENDE, 2009).

Via de regra, baseadas pelos preceitos da indústria automotiva adicionados com as normatizações específicas referentes à sua área de atuação, as empresas criam seus próprios modelos de manufatura, estipulados estratégicamente, que têm por finalidade tornar a empresa mais competitiva respeitando suas características e capabilidades já existentes ou buscadas.

Sob esse aspecto, no ano de 1989, de acordo com Cardoso (2004), o Grupo Fiat decidiu implantar o modelo ohnoísta de produção, mas, percebendo que os conceitos japoneses não eram 100\% aplicáveis na Itália, foi pensado em um modelo de fábrica enxuta (azienda corta), que posteriormente foi também implantado na sua maior filial, no Brasil, sendo considerado um modelo híbrido, pois funde princípios produtivos pós-fordistas e não somente japoneses. Já a criação do sistema global de manufatura (GMS), da General Motors, ocorreu em 1996 e partiu do princípio de que todas as plantas da GM fazem parte da mesma companhia e devem operar em um único sistema de produção com elementos comuns, ou seja, é uma estratégia global de manufatura. Os sistemas produtivos da indústria automotiva, via de regra, seguem o paradigma vigente: no atual momento, o sistema Toyota de produção.

\section{Estudo de caso: transposição das metas de custos para o chão de fábrica}

\section{Sistema global de manufatura}

A General Motors do Brasil dispõe de uma metodologia própria de implantação da produção enxuta. É chamada de global manufacturing system (GMS), que busca fortalecer a empresa por meio de 33 elementos dispostos em 5 princípios, que são: padronização; comprometimento das pessoas; feito com qualidade; menor tempo de execução; e melhoria contínua. Para a implantação dessa metodologia de produção enxuta, a GM trabalhou com a ferramenta business plan deployment (BPD) - desdobramento do plano de negócios -, que permite disseminar e acompanhar as melhorias de forma sistemática (GMB, 2009).

No entanto, esse guia de processos chamado GMS não dispõe de constructos definitivos quanto a quais indicadores devem ser utilizados para cada time de trabalho no que tange a custos, sendo, assim, alvo de controvérsias entre os gestores a escolha de um ou de outro método de medição.

\section{Desdobramento do plano de negócios (BPD)}

Segundo o manual de manufatura da GMB (2009), o business plan deployment é a ferramenta que permite o desdobramento dos planos da empresa até o nível operacional, permitindo, assim, que cada nível da organização contribua com o resultado geral dentro dos princípios do GMS. Kaplan e Norton (1997) usam a nomenclatura alinhamento estratégico, que definem como o método que possibilita a comunicação da estratégia e a sua vinculação com as metas pessoais.

Akao (1997), em seu livro sobre TQM, fala sobre hoshin kanri, que ele denomina de desdobramento das diretrizes que são divididas em dois níveis: o primeiro é o planejamento estratégico; e o segundo, o gerenciamento diário dos aspectos mais básicos da operação do negócio. O BPD é um processo sistematizado que permite uma visualização da organização, composta de múltiplas partes, atuando de forma harmônica para alcançar os objetivos da companhia dentro das cinco categorias definidas: segurança, qualidade, custos, capacidade de resposta, desenvolvimento de pessoas e meio ambiente (GMB, 2009).

Essa ferramenta é estruturada por key performance indicator (KPI), cabendo à alta direção definir 
quais serão os "indicadores-chave de desempenho", pois em uma empresa podem existir diversos indicadores que, de alguma forma, apontam resultados e apoiam diagnósticos. Devem ser eleitos como KPIs apenas aqueles que o seu atingimento seja capaz de alinhar a empresa com a sua visão e os seus objetivos estratégicos, permitindo a fácil compreensão de todos.

O BPD:

- permite definição de metas globais para toda a empresa;

- permite o desdobramento dessas metas a todos os níveis da empresa;

- coloca toda a empresa em uma mesma direção.

Descrição das partes integrantes do processo BPD (GMB, 2009):

- visão e sistemas de valores: a visão e o sistema de valores fornecem a base de todas as atividades da organização. Eles são a base para o modelo de 76 negócios que fornece a identidade e a direção estratégica que distingue uma companhia de seus competidores ou de companhias em outros ramos de atividade;

- prioridades de negócios: são definidas pela alta gerência. Essas prioridades focam a organização naquilo que se deve ser realizado para atingir a visão;

- plano de ações e negócios: planos específicos dos negócios e ações definem os objetivos de cada setor, grupo, divisão e organização. Por meio do atendimento desses objetivos, cada pessoa da GM está ligada à realização da "visão da GM";

- satisfação total do cliente: o cliente final,comprador e usuário de nossos produtos e serviços, é o árbitro final da performance de nosso plano de negócios. Nossos clientes finais nos fornecem os dados que nos dizem se o desempenho de nosso plano de negócios está alcançando o objetivo.

\section{Quadros de indicadores de desempenho de times de trabalho}

Os quadros de indicadores de desempenho de times de trabalho são grandes instrumentos de disseminação do BPD dentro da empresa, pois com um bom gerenciamento visual se permite que a cultura, os princípios e as metas da corporação sejam multiplicados. O quadro de indicadores de desempenho de times de trabalho (QIDT'T) faz parte de uma gama de ferramentas visuais do sistema enxuto de produção, tais como: kanbam, andom, fluxogramas, mapeamentos de valor e quadros de procedimento de operação fixados nas células de trabalho, todos eles objetivando criar um ambiente sem perdas e de fácil administração, pois os desvios são facilmente identificados. Qualquer que seja a forma de acompanhamento, os valores do item de controle devem ser colocados de tal maneira que basta um olhar para entendê-los (CAMPOS, 2004).

Os quadros objetivam ser didáticos e/ ou informativos e ser utilizados como um canal de duas vias entre os gestores e operadores. O controle visual é qualquer dispositivo de comunicação usado no ambiente de trabalho para nos dizer rapidamente como o trabalho deve ser executado e se há algum desvio de padrão. Podemos definir "gerenciamento visual" como um sistema de planejamento, controle e melhoria contínua que integra ferramentas visuais simples que possibilitam que se entenda, por meio de uma rápida "olhada", a situação atual e o que apoia o trabalho padrão da liderança para garantir a aderência dos processos aos padrões e viabilizar as melhorias permanentes (LIKER, 2005).

Os quadros devem ser preenchidos diariamente, visto que, segundo Akao (1997), fazem parte de um gerenciamento diário de todas as atividades que objetivam que cada departamento deva realizar individualmente, em uma base diária, suas metas de trabalho. Essas atividades são as mais fundamentais do gerenciamento empresarial.

Cada categoria do quadro - segurança, desenvolvimento das pessoas, qualidade, capacidade de resposta, custos e meio ambiente-, está posicionada em uma coluna vertical e cada fase do PDCA está postada horizontalmente.

\section{ISO 9001:2008 e a relação com o quadro de indicadores de desempenho de times de trabalho}

O item 8.1 da ISO 9001:2008 determina que a organização deve planejar e implementar os processos necessários de monitoramento, medição, 
LUZ, D. F. da.

análise e melhoria, para demonstrar a conformidade do produto, assegurar a conformidade da gestão da qualidade e melhorar continuamente o processo de gestão da qualidade. As medições de processos, quando aplicáveis, devem ser usadas para gerenciar operações diárias, justamente a que se propõe o QIDT'T.

A nota do item 8.2.3 orienta que, ao determinar métodos adequados, é recomendável que a organização considere o tipo e a extensão de monitoramento ou medição apropriado para cada um de seus processos em relação aos seus impactos sobre a conformidade com os requisitos do produto e sobre a eficácia do sistema de gestão da qualidade. Visto que a versão da NBR ISO 9001-2008 foca a gestão por processos, a utilização de QIDT'T tornase de grande importância para o atendimento das exigências de certificação, pois permite distinguir e monitorar cada célula de trabalho dentro da organização e suas relações com os clientes internos e externos da desta.

Há uma grande dificuldade dos gestores em transportar as responsabilidades por custos sofridas nos níveis estratégicos e táticos para o nível operacional, visto que faltam indicadores possíveis de serem levados ao chão de fábrica que sejam padronizados e testados amplamente. $\mathrm{Na}$ General Motors não foi diferente, pois apesar de possuir um manual de procedimentos de manufatura-GMS -, a dúvida sobre quais indicadores de despesas operacionais utilizar é constante e ainda gera debates, visto, também, que faltam literaturas mais robustas abordando a microeconomia da empresa. Goldratt (1990) define despesas operacionais como todo o dinheiro que é gasto para transformar inventário em ganho.

O setor de trabalho a ser apresentado neste artigo é da área de manutenção de ferramentas de estampagem da linha de modelos Celta e Prisma, atuando nas manutenções preventivas, corretivas e melhorias dessas ferramentas, que produzem em duas linhas de prensas uma transfer (cinco estágios sequenciados e interligados) e outra tanden line (quatro estágios sequenciados, mas independentes), a produção da empresa é atualmente na faixa de 52 carros por hora. A equipe é composta, neste momento, por 34 técnicos divididos em 5 equipes de trabalho, responsáveis por 183 ferramentas, cada uma das equipes com seu quadro de indicadores de desempenho.

$\mathrm{Na}$ empresa pesquisada, a divisão da organização é baseada em centros de custos. Os budgets são alocados nos departamentos. Normalmente os departamentos são determinados considerando-se o organograma, a localização, a responsabilidade e a homogeneidade.

No que se refere à medição de desempenho na categoria custos, cada setor possui seus indicadores e, no caso específico do setor de estamparia, a produção e ferramentaria é por EPIs - equipamento de proteção individual - e scraps - peças sucateadas -, já a manutenção é por materiais mais comumente utilizados (sensores de presença e esteiras) e por EPIs. Essa medição utilizada na manutenção, baseandose também em materiais de consumo de reparo, é bastante discutível e foi rechaçada no setor de ferramentaria, pois gera um trade off desnecessário sob o ponto de vista de vários gestores, visto que inibe a manutenção de agir em cima de problemas gerados por materiais de consumo por questões de custos, pois cada sensor ou esteira trocados os afastariam ainda mais de seu target mensal de custos, gerando os chamados ótimos locais.

$\mathrm{O}$ valor estipulado tem se mostrado insuficiente em razão da ainda grande quantidade de scraps de peças gerados pelo setor, pois o modelo de produção utilizado na GM de Gravataí dificulta a percepção de peças não ok durante o processo, pois se trata de linhas de prensas transfers/tandem fechadas, que só possibilitam a visualização do estampado após passar pelos seus quatro ou cinco estágios e mais a esteira de transporte. Sendo assim quando o operador pega uma peça não ok no final da linha há no mínimo mais quatro peças não ok a serem contabilizadas.

A utilização de dados de gastos de EPIs, apesar de se mostrar de menor peso no conjunto dos indicadores, é de grande importância na totalização de valores gastos mensalmente em virtude da sua indicação de melhoria de fluxo de estoques dentro da empresa, visto que demonstra claramente áreas que estão estocando materiais indevidamente, indo contra a metodologia usada na empresa para controle dos sete desperdícios de Shingo.

\section{Metas}

A meta de custos corresponde ao controle dos gastos do item que mais impacta ao time com relação a custos. Cada time possui uma quantidade máxima de $\mathrm{R} \$$ a serem gastos com o item estabelecido. 


\section{Acompanhamento do resultado}

$\mathrm{O} \$$ deve ser pintado de verde ou vermelho quinzenalmente. $\mathrm{O}$ verde deve ser usado quando o time atingir a meta, ou seja, quando gastar um valor igual ou inferior à meta estabelecida no fim do mês ou um valor igual ou inferior a $50 \%$ da meta estabelecida no fim da primeira quinzena. O vermelho deve ser usado quando a meta não for atingida, ou seja, quando o time gastar mais.

Tabela com o registro quinzenal: preencher o valor gasto pelo time com o item que mais impacta nos seus custos em cada quinzena.

\section{Acompanhamento mensal}

Diamante mensal: preencher em verde os meses em que o valor gasto pelo time com o item controlado no quadro for inferior ou igual à meta; $\mathrm{e}$ em vermelho os meses em que for superior à meta.

Tabela com o registro mensal: preencher o valor total gasto pelo time com o item controlado em cada mês.

\section{Acompanhamento visual mensal}

Utilizar o círculo verde quando a meta do mês anterior for atingida, ou o " $\mathrm{x}$ " vermelho quando não for.

\section{Plano de ação}

O plano de ação é aberto quando a meta quinzenal do time não for atingida, ou seja, quando o time gastar mais do que $50 \%$ da meta na $1^{a}$ quinzena ou mais do que a meta mensal no fim da $2^{a}$ quinzena. O plano de ação deve conter a data de abertura da ação, descrever o item NOK, a ação tomada e o responsável pela ação. O acompanhamento da resolução do problema é feito nas colunas de data, onde devem ser preenchidas a data de previsão do fechamento da ação e a data em que a ação foi realmente encerrada.

\section{Ganho ou benefício}

Levaro gerenciamento por metas até o nível de time, fazendo com que tenha responsabilidades de custos. Esses quadros são preenchidos diariamente porum operador orientado pelo coordenador da área, que busca informações dispostas no sistema. Esse método de repassar a responsabilidade pelo controle do quadro ao operador visa a um engajamento maior por parte de todos os membros do time, pois há um rodízio mensal de responsáveis pelo quadro.

Observa-se que as construções de indicadores de custos não se baseiam em constructos mais elaborados, mas somente em médias históricas dessa planta e de outras pesquisadas na região da América Latina, África e América Central (LAAM), usando-se o referencial do benchmarking.

\section{Considerações finais}

No corpo do trabalho foram sintetizados indicadores de desempenho, sistema global de manufatura (GMS), desdobramento do plano de negócios (BPD), quadros de indicadores de desempenho de times de trabalho e o círculo PDCA, para poder explorar de forma mais específica o indicador de custos do quadro de time da ferramentaria/estamparia GMB. O modelo de construção do índice de custos permitido para a ferramentaria baseou-se em um cálculo que leva em consideração somente o gasto com EPIs e scraps, visto a dificuldade dos gestores em incorporar outras métricas nesse processo de mensuração de custos. Ainda que a contabilização de valores de EPIs se mostrar pouco significativa na questão financeira, mas do ponto de vista de conscientização dos funcionários quanto à utilização dos recursos de forma racional, ela se mostra satisfatoriamente eficiente.

É importante frisarque o desdobramento da estratégia de manufatura busca promover a excelência em processos que em muitas organizações se mantêm obscuros em razão do olhar do gestor somente para questões macro. A criação pelas empresas de seu próprio sistema de produção facilita esse processo, visto que normatiza e lineariza as ações internas.

A utilização de quadros de indicadores de desempenho de times de trabalho na General Motors tem se mostrado eficiente na implementação dos processos que envolvem o monitoramento e o diagnóstico de problemas inerentes à linha de produção de uma grande indústria, pois facilita que todos os membros de times comunguem dos mesmos valores e objetivos. Percebe-se mais presente no coletivo a 
preocupação em dados e números normalmente desprezados por trabalhadores do chão de fábrica, pois como esses dados ficam expostos e são cobrados obedecendo ao ciclo PDCA eles se tornam incorporados na rotina de trabalho, dando resultados financeiros objetivos.

\section{Referências}

ANTUNES Jr., J. A. V.; KLIPPEL, M. Os custos e a tomada de decisão: uma abordagem histórica a partir da evolução conceitual das filosofias e dos métodos de custeio. 2. ed. São Leopoldo: PPGEP/Unisinos, 2002.

ANTUNES Jr., J. A. V.; CAULLIRAUX, H.; NEVES, M. A organização por processos, grupo de produção integrada. São Paulo: COPPE-EE/UFRJ; SAP Universe, 1998.

AKAO, Y. Desdobramento das diretrizes para o sucesso do TQM. 2. ed. Porto Alegre: Artes Médicas, 1997.

ASSOCIAÇÃO BRASILEIRA DE NORMAS TÉCNICAS - ABNT. NBR ISO 9001: sistemas de gestão da qualidade - requisitos. São Paulo, 2008.

ATKINSON, A. A. Contabilidade gerencial. 2. ed. São Paulo: Atlas, 1998.

BITITCI, U.; SUWIGNJO, P.; CARRIE, A. Strategy management through quantitative modelling of performance measurement systems. International Journal of Production Economics, New York, v. 5, n. 69, p. 15-22, 2001.

BORNIA, A. C. Análise gerencial de custos: aplicação em empresas modernas. 2. ed. São Paulo: Atlas, 2009

CAMPOS, V. F. Gerenciamento da rotina de trabalho do dia-a-dia. 2. ed. Nova Lima: INDG Tecnologia e Serviços, 2004.

CARDOSO, L. A. A reestruturação pós-fordista da produção e suas conseqüências sobre as novas formas de gestão de projetos na indústria automobilística brasileira: o caso da FIASA - Fiat Automóveis S. A. In: SIMPÓSIO DE ENGENHARIA DE PRODUÇÃO, 11., 2004, Bauru, SP. Anais... Bauru: SIMPEP, 2004.

GHINATO, P. Sistema Toyota de produção: mais do que simplesmente just-in-time. 2. ed. Caxias do Sul: EDUCS, 1996.
GOLDRATT, E. M. What is this thing called theory of constraints and how it should be implemented? North River Press, New York, v. 8, n. 4, p. 68-83, 1990.

GENERAL MOTORS DO BRASIL - GMB. Manual do sistema global de manufatura - GMLAAM. Gravataí: GMB, 2009.

GUARNIERI, P.; HATAKEYAMA, K.; RESENDE, L. Estudo de caso de um condomínio industrial na indústria automobilística: caso GM Gravataí. Revista Produção Online, Gravataí, v. 9, n. I, p. 65-93, 2009.

LIKER, J. K. O modelo Toyota - 14 princípios de gestão do maior fabricante do mundo. 2. ed. Porto Alegre: Bookman, 2005.

LUZ, D. F. da. Proposta de melhoria de equipamentos críticos através do método de gestão dos postos de trabalho, STP e TOC: um estudo de caso de uma empresa automotiva. In: SIMPÓSIO DE ENGENHARIA DE PRODUÇÃO, 17., 2004, Bauru. Anais... Bauru: SIMPEP, 2010.

KAPLAN, R. S.; NORTON, D. P. A estratégia em ação: balanced scorecard. 3. ed. Rio de Janeiro: Campus, 1997.

MIYAKE, D. I. The deployment of corporate production systems in auto industry companies: an approach to drive process improvements towards operational excellence. Int. J. Automotive Technology and Management, New York, v. 8, n. 4, p. 431-448, 2008.

SHINGO, S. Sistema Toyota de produção do ponto de vista da engenharia de produção. 2. ed. Porto Alegre: Bookman, 1996.

SLACK, N. Vantagem competitiva em manufatura: atingindo competitividade nas operações industriais. 2. ed. São Paulo: Atlas, 2002.

RODRIGUES, M. B. Just-in-time: nova forma de organização de trabalho. 1991. 226 f. Dissertação (Mestrado em Administração) - Universidade Federal do Rio Grande do Sul, Porto Alegre, 1991.

YIN, R. K. Estudo de caso: planejamento e método. 2. ed. Porto Alegre: Bookman, 2001.

Recebido: 19/10/2010 Received: 10/19/2010

Aprovado: 15/12/2010 Approved: 12/15/2010 